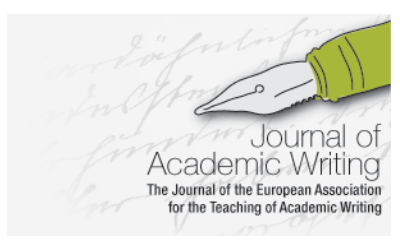

Journal of Academic Writing

Vol. 1 No 10 WINTER 2020, pages 195-202 https://doi.org/10.18552/joaw.v10i1.643

\title{
Translingualism in Three University Roles: Pedagogical Postures and Critical Cautions
}

\author{
B. Cole Bennett \\ Abilene Christian University, USA
}

\begin{abstract}
This paper offers and develops some useful parameters toward the ongoing conversations on multilingual and multidialectal writing students in Europe and the United States, two settings which produce oft-competing views of writers' varied language backgrounds. I present a synchronic snapshot of writing pedagogy as it relates to translingualism at this temporal moment. Specifically, I seek to link three different university roles - classroom teachers, writing center directors, and writing across the curriculum (WAC) directors - to certain translingual postures and their consequential applications. By introducing and elaborating upon the labels Traditionalist, Allied Enthusiast, and Active Advocate as they attend each role, I wish to offer helpful ways to understand the consequences of embracing these postures. This charting of stakeholders and their characteristics can more readily facilitate concrete scholarly discussion concerning translingual writing instruction as it moves forward. I conclude with recommendations and cautions, bringing into question some of the settled assumptions remaining in our field.
\end{abstract}

\section{Introduction}

In recent years, Western academics have embraced competing approaches toward writing students' varied language backgrounds. Some scholars value a writer's facility with multiple languages, dialects, and rhetorics as rich contributions to the process of producing, ultimately, audience-tailored academic prose. Others, particularly Rhetoric-Composition scholars in the United States, see nonstandard linguistic assets as important links to marginalized identities to be displayed regardless of, and sometimes in opposition to, reader expectations. What began in 1974 as an attempt to illuminate linguistic truths about students' "home languages" and "rights" in the US (National Council of Teachers of English, 1974) has become a fast-growing avalanche of trenchant scholarship concerning translingualism, a term defined recently as "dispositions, theories, and frameworks that propose inclusive approaches to the use of multiple languages...in spite of monolingual efforts to invalidate non-Standard Academic English" (Medina, 2019, p. 74). Based on earlier seminal work by Horner et al. (2011), Lu and Horner (2016), Canagarajah (2009), Young (2011), and many others, translingual scholars seek to criticize the historical and political avenues by which Standard Academic English (SAE) rose to prominence, to address the lopsided material conditions in which students learn to write, and to embrace the responsibility to advocate for the legitimacy of multiple languages in writing classrooms (for productive longitudinal syntheses of this movement, see Hall (2018), and Williams and Condon (2016)). Crossing Divides: Exploring Translingual Writing Pedagogies and Programs, Horner and Tetreault's (2017) recent edited collection of Rhetoric-Composition scholarship, provides a useful illustration of where these discussions have led: richer articulations of theory, pedagogy, and systemic programs, as well as clearer definitions of terms and vocabulary, program assessment, and student agency.

Concerns toward rectifying social ills and/or reversing the effects of colonization (see Medina, 2019, for example) have gained little traction in most non-US discussions of academic multilingualism. Rather, European scholars write of the usefulness of contrastive rhetorics and 
multiple language facilities within the writing process to achieve written products ultimately suitable for one's audience. In one article, for example, German authors describe research results regarding a physicist in the scientific community who "integrates his individual language repertoire in his writing practice to produce a text in a target language (in most cases in English)" (Brinkschulte et al., 2018, p. 155):

As Daniel uses his three languages in his daily work he feels familiar with them and is able to decide which expression might be the most precise one [to describe his research content]. For his individual writing he uses his available languages for writing a draft, keeping in mind the necessity to translate it into the target language English when he wants the paper to be published. (p. 156)

These authors refer to their program at Gottingen University as an example of a translingual writing course, but they use the term differently from US scholars. While they acknowledge the benefit of having writers reflect on their sociocultural links to language, in the end, the exigency of audience-directed writing prevails: "We focus on enabling students to activate their multilingual resources for their individual writing processes and to choose suitable writing strategies according to their writing situation and writing context" (p. 158). A final draft that satisfies reader expectations, whether in the writer's L1 or some other language or dialect, serves quite a different goal from that of celebrating or asserting a writer's identity through discourse.

Some US-based second-language writing (SLW) scholars have also begun to sound alarms at the translingualist movement as they see its incautious boundaries and liberationist aims as interference to rhetorical success (Atkinson \& Tardy, 2018; Matsuda, 2014). And those who try to find middle ground still question the efficacy of privileging translingual motives over the students' own desire for proficiency: "If students want to engage in codemeshing, then the teacher should create space for that. But if they wish to learn dominant discourses, then that choice needs to be respected too. We must acknowledge that our students face social, economic, and educational pressures to compose in SWE" (McIntosh et al., 2017, p. 17).

This essay seeks to demarcate some important parameters of this ongoing conversation concerning multilingual student writers - parameters on display in both US and European contexts where academic writing is taught as SAE, ELF, or EAP. Inspired partially by Hall's (2018) call to clarify and make explicit the relationships among disciplines and systems, I offer a synchronic snapshot of writing pedagogy as it relates to multilingual writers in general and translingual pedagogy specifically. My goal is to link various university roles - classroom teachers of academic writing, writing center directors, and writing across the curriculum (WAC) directors - to certain postures and their attendant consequences. I will then discuss the effects of embracing each posture in turn, throwing into question some of the settled assumptions remaining in our field and emphasizing some cautions arising therefrom. I conclude by presenting to the reader what I hope is a well-wrought case for a particular stance from the choices discussed.

\section{Three Roles in Three Postures}

Below is a graphic representation that intends to capture the present disciplinary moment of scholarly discussion by linking three university roles to consequential points along a translingual/multilingual continuum (see Table 1). Drawing on years of responses to language difference and the historical treatment of students who have come to school without facility in an elite dialect, I have distilled three unique postures and the practicalities of each. Though necessarily reductive, I seek to concretize some of the abstractions that appear in scholarly calls to embrace translingualism, while also recognizing some of the pragmatic applications that have been put forward. The importance of making explicit these positions and their related attitudes in one graphic lies in its ability to cut through a fast-moving rush of scholarship, most of which varies in focus by geographic region, and some of which seems new to some (such as US rhetoric-composition scholars) but settled by others (such as European scholars of academic writing and second language writing throughout the West). 
Table 1

Translingual Positions in University Writing Roles

\begin{tabular}{|c|c|}
\hline Traditionalist & $\begin{array}{l}\text { Classroom: Craft lectures and model essays that heavily } \\
\text { reinforce the need for adherence to Standard Written English } \\
\text { (SWE). Regularly drill students on focal grammar and usage and } \\
\text { structure grading to reward close adherence to standard } \\
\text { sentence production. } \\
\text { Writing Center: Emphasize the need for correctness at every } \\
\text { stage of writing and tutoring. Train tutors to see students' } \\
\text { multilingual assets as largely incidental to the task of producing } \\
\text { appropriate responses to prompts, including correct SWE } \\
\text { sentences. } \\
\text { WAC: Help faculty design prompts and grading protocols that } \\
\text { focus largely on SWE-based interpretations of language-related } \\
\text { university outcomes. }\end{array}$ \\
\hline Allied Enthusiast & $\begin{array}{l}\text { Classroom: Emphasize the linguistic value of other languages, } \\
\text { dialects, and codes, and encourage translingual process and } \\
\text { drafts, if helpful, while still requiring final texts in EAP/SWE/ELF. } \\
\text { Writing Center: Welcome and support the value of all } \\
\text { languages, dialects, and codes while always respecting the } \\
\text { validity of academic audience(s) normally represented in } \\
\text { university assignments. Hire multilingual tutors to assist as } \\
\text { needed with multilingual writers through the writing process and } \\
\text { toward a final draft in SWE. } \\
\text { WAC: Promote the inherent value of all languages while } \\
\text { respecting the powerful role of SWE currently embraced by most } \\
\text { faculty and reflected in most university outcomes. }\end{array}$ \\
\hline Active Advocate & $\begin{array}{l}\text { Classroom: Assign scholarly readings and writing assignments } \\
\text { that focus on meta-issues of translingualism. Strongly } \\
\text { encourage or require more than one language, dialect, or code } \\
\text { in final written texts. } \\
\text { Writing Center: Hire multilingual tutors who represent a large } \\
\text { swath of world languages. Train all tutors to encourage home } \\
\text { languages and dialects in writers' academic essays, and to } \\
\text { advocate for translingual practices across campus. } \\
\text { WAC: Purposefully educate faculty across campus about the } \\
\text { value of translingualism, then ask them to include reading and/or } \\
\text { writing assignments that welcome non-SWE languages, } \\
\text { dialects, or codes. }\end{array}$ \\
\hline
\end{tabular}

The table's left column labels the relationship toward translingualism found in the university roles in the right column. The Traditionalist, therefore, could be said to have no relationship at all, or even perhaps an adversarial one, with this pedagogy. In each role, Traditionalist writing instruction creates and maintains an emphasis on an elite, formal style, often Standard Written English (SWE), expected by most academic audiences, real or imagined. Classroom teachers see their role as helping students master the grammar, syntax, punctuation, and overall word 
choice attached to this dialect, and its position as "elite" or "artificial" or even "created via colonial power systems" remains categorically irrelevant. Writing Center personnel are quick to identify writers' stylistic errors in their essays, having abundant resources on the shelf and in the files to help overcome such errors. Early drafts brought to the writing center in other languages would likely be discouraged, seen as slowing down the pace to SWE competence. Finally, WAC directors embrace either the perception of SWE as a social norm, or else their respective university's explicit outcomes that demand "Competence with spoken and written communication in Standard Academic English" (or similar wording). Hence, the design of, and input toward, WAC institutional policies would solicit the production of error-free SWE at every step.

The middle posture I label Allied Enthusiast. Here, classroom teachers and writing centers communicate an openness to students' use of any language, dialect, or code as they undertake the writing process to ultimately produce a final product that adheres to the expectations of the audience. This stance need not require teachers or tutors to approve or disapprove of the writers' home linguistic assets; on the contrary, invention strategies and exploratory drafts can be composed in whatever language or dialect they find in common, even if the writer is at first producing a nonstandard or multilingual text. As writers move through iterations of drafting and revising, attention to the rhetoric(s) and stylistic features of students' home languages and dialects are welcome resources of meaning-making. The move to a final draft still revises "nonstandard usage," but deviations are not characterized as "error." WAC directors are still beholden to university outcomes regarding effective communication in SWE, but they are more hospitable to notions of nonstandard or multilingual "work products" that eventually lead to rhetoric and writing in SWE. Part of their WAC role is to educate writing faculty on broader points of linguistic theory that highlight contrastive rhetoric. ${ }^{1}$

With critical theory readings woven into each composition syllabus, the Active Advocate classroom teacher would emphasize the colonial history, racism, and classism associated with the rise of elite dialects for academic purposes. The objective is to deauthorize and decenter these dialects, bringing their very preference by high-stakes audiences into question. In like fashion, writing center personnel are expected to (and receive the training to) help writers recognize the potentially oppressive structures in the university system that devalue nonstandard languages and dialects. Tutors also encourage writers to mesh nonstandard and standard writing in order to assert their identities and resist the unjust power structures that artificially placed the latter in its privileged position. Such advocacy might also include lobbying professors who expect academic prose to make room for such meshing in order to allow marginalized students' home dialects to gain legitimacy in larger realms of power. Active Advocate writing centers aim to be an institutional change agent, seeking to "explain, demystify, and clarify translingualism for the whole institutional community" while "reconstructing traditional theories and practices in second language acquisition" (Newman, 2017, p. 9).

WAC directors, who usually exert indirect influence on writing programs, play a more pointed role at this level of advocacy, persuading writing professors to adopt a more "progressive" view on what counts as "effective writing" and to support grading standards that reflect this view. Professors who continue to demand SWE in final textual products are then viewed as contributing to the marginalization of non-fluent SWE writers. WAC directors have the added responsibility of liaising with university administration and curriculum committees, each of which holds sway over macro-level changes to university outcomes; thus, this directorship could influence top-down systemic changes as an integral part of its purview.

Implied throughout the roles in Table 1 is another important stakeholder without whom my argument would be incomplete - the university student. Year after year, students enroll in

\footnotetext{
${ }^{1}$ This middle position does not duplicate Horner et al.'s (2011) description of a perspective that merely "tolerate[s]" or "accommodate[s]" nonstandard prose (p. 306), nor does it "perpetuate monolinguist tenets" by focusing on various abstractions of decontextualized languages to be permitted (Horner, 2017, p. 88); the term Enthusiast is meant to indicate a welcome embrace of language features, not a mere resignation to a changing landscape.
} 
composition-rhetoric courses designed and executed by writing professionals whose stated purpose is to teach students rhetorical discourse. These teachers and courses influence protocols in an institution's WAC program, while writing centers help writers move toward their rhetorical goals in accordance with the centers' own public mission statements. By enrolling in a university, students validate, explicitly or implicitly, the outcomes articulated by its composition-rhetoric course programs, support systems, and university-level literacy outcomes. The institutional roles listed in Table 1, then, exert considerable influence on the writing student, but an influence different from primary school systems. The latter consists usually of children marching through regimented state-designed and approved curriculum, exams, and placements, but the university welcomes young adults making educational choices with tuition in hand; they select programs of learning they believe will most aptly help them realize their own ambitions, both personal and professional. I am not claiming merely that our students are "customers" who must be "satisfied"; rather, they are the most important stakeholders in the learning they have chosen.

\section{Embracing a Path: A Recommendation}

I now wish to make plain what I believe is the most productive way forward for writing professionals, providing reasons for the posture I favor and calling out the risks with the other two positions. At my university in Texas, I happen to inhabit all three roles listed on Table 1: I teach all levels of writing, from first-year composition, to professional writing, to graduate composition theory; I direct a medium-sized writing center and have done for 20 years; and I direct our university's writing across the curriculum program. In each theater, I encounter students with many varied language abilities - bilinguals, true multilinguals, English language learners, and those fluent in one or more nonstandard English dialects. From the years I have worked beside and consulted my colleagues, both in the US and Europe, I am convinced that the middle posture, Allied Enthusiast, is the way forward, whether SWE or some other elite dialect is the academic expectation.

The Allied Enthusiast classroom teacher understands that a student's use of nonstandard prose is not necessarily a case of error but could be illustrative of his or her home discourse - perhaps even careful, adroit use of this discourse. Such a teacher helps the writing student understand the purposes, parameters, and audiences of the assignments and expressions of rhetoric that would most suit the exigency at hand. A focus on "correct" forms is minimized in prewriting and drafting work products as years of phenomenological research validates (for a detailed exploration of this topic, see, for example, the Special Issue of The English Journal, Christenbury, 1996).

The Allied Enthusiast teacher also considers ways in which writing assignments might even be better addressed via non-elite dialects: for example, a common first-year writing prompt in American universities asks students to draw upon personal experience to make an argument about their early literacy education. Students who choose to interweave dialects that vary from SWE as they answer such a prompt might very well improve the ethos of their essays by appearing more authentic to the reader. Moreover, certain segments of digital essays, evermore popular in composition classrooms, which combine written, visual, and aural media to compose arguments, might be more suited to less stilted, nonstandard dialects.

Likewise, an Allied Enthusiast writing center director has far more interest in assisting writers in their quest for successful written rhetoric than upholding abstract standards of SWE for their own sake or explaining to each writer the language-based oppression that has led to the privileging of elite dialects in western academies (Bennett, 2008; Davila, 2006). Many writers who meet with a tutor to improve their drafts do indeed seek SWE mastery, but others come to work on memoirs, poetry, creative nonfiction, journalistic pieces, or other prompts whose parameters might welcome other dialects and languages. This is why careful agenda setting forms such a crucial part of a writing center session; the tutor's primary task is to help the writer find and meet his or her rhetorical goals with the texts under review, always listening along the way. Engaging in such purposeful conversation can alert both tutor and writer to instances where rhetorical exigencies might best be met with home languages or nonstandard dialects. 
The Allied Enthusiast WAC professional adopts a more advisory role, seeking to validate classroom teachers' own unique methods of process writing - including the use of nonstandard forms in early work product when appropriate and useful - to help students arrive at textual products meeting both classroom prompts and published university outcomes toward language competencies.

A common argument I have encountered against my position is that academic language-arts professionals should exercise our license to expand the views of students who may not realize the oppressive nature and racist background that infuse SWE. My response to such criticism is steadfast: while we may indeed be experts in our fields, steeped in the latest scholarship on translingual writing, classroom power differentials, and critical race theory, we are certainly not experts in our students' individual aspirations. Our primary aim as rhetoric teaching professionals should not be to spend time convincing students of their status as language victims, advocating for the use of their home dialects within academic assignments as a way to fight back (Blazer \& Fitzgerald, 2015). These burgeoning writers enroll in our rhetoric courses and seek writing center assistance for their own reasons, often including proficiency in SWE; we should honor those reasons.

Having indicated my own preferred stance, I conclude with a vignette that illustrates nuances that might well obtain in the various professional roles mentioned above. Anna, an undergraduate advisee, came to me a few semesters ago to discuss her upcoming class schedule. She explained that she had taken a year off to become healthy after an accident, but that she had no plans to quit. "My family lives in Mexico," she said, "and they are counting on me. I am here to better my English, to learn to write well so that I can succeed in this country. My family and I know it's the way to success." As an Allied Enthusiast, I was struck by the need to hear and discuss Anna's goals with her, respect her first language as an asset, and help her learn discourse that most helps her respond to her rhetorical exigencies, even if that discourse falls neatly into SWE. Assisting her this way does not make me a Traditionalist; my commitment is to Anna, not an abstracted academic dialect. I would deem my Allied Enthusiast posture most appropriate for classroom teachers and writing center professionals, each of whom reflects and prioritizes the overall wishes of writers seeking improvement.

However, because a writing center has room to explore options with Anna due to its less formal environment, Active Advocates can also find rich footing. If Anna had expressed a desire to combine her home language with academic prose to fulfill a writing prompt, or even if she had never considered such a move, such tutors might indeed find ways to help her mesh multiple languages and dialects to assert her voice. Moreover, had Anna come from, say, a linguistics class asking about the power dynamics that cause her first language to be unwelcome in most formal research papers in a Texas university, Active Advocates would stand most ready to embrace such a conversation in depth; their encouragement might lead to Anna's own reevaluation of her academic voice.

A WAC director would occupy the least nimble role when considering Anna's situation: answering to many institutional stakeholders, he or she might inhabit the Traditionalist role more than the others. However, considering both longitudinal data of university writing outcomes and more recent calls for improving the status of non-elite discourse, this professional might use case studies like Anna's situation to make small movements toward the other two positions. A writer like Anna, who can use multiple aspects of her identity in discourse, might thus actually help lead a university away from Traditionalist policy positions in writing courses.

My own preference for the Allied Enthusiast position rests upon its placing the student in the center. Indeed, I would argue that a writing professional's motivational focus determines his or her Table 1 position more than any other factor: the Traditionalist focuses upon a body of rules and traditions, the Allied Enthusiast upon the students' goals, and the Active Advocate upon a view of left-leaning liberation that may or may not coincide with the students' own wishes.

The multiple languages and dialects students might employ, as well as their ability to nimbly code switch and/or code mesh as they create discourse, are indeed assets that can be explored 
as contrastive rhetoric elements. However, such elements are not an end unto themselves for most audiences. Translingual scholars should not levy charges of racism or colonial violence toward writing professionals whose guidance yields students' learning elite rhetorics of power. Classroom teachers, writing center directors, and WAC professionals contend daily with the success and failure of students who wish to meet the rhetorical needs of audiences, often via prose completed in SWE. These writers yearn to master this fluency because they see wellparlayed phrases, arguments, and essays in this dialect as necessary traits of those who pursue their own paths forward. 


\section{References}

Atkinson, D., \& Tardy, C. (2018). SLW at the crossroads: Finding a way in the field. Journal of Second Language Writing, 42, 86-93. https://doi.org/10.1016/j.js/w.2018.10.011

Bennett, B. C. (2008). Student rights, home languages, and political wisdom in the writing center. The Writing Lab Newsletter, 32(5), 7-10.

Blazer, S., \& Fitzgerald, L. (2015). Identity, critical literacy, and the pursuit of inclusion and justice in writing centers. College English, 78(2), 183-195. https://www.jstor.org/stable/44075106

Brinkschulte, M., Grieshammer, E., \& Stoian, M.-E. (2018). Translingual academic writing at internationalised universities: Learning from scholars. Journal of Academic Writing, 8(2), 150-160. https://doi.org/10.18552/joaw.v8i2.460

Canagarajah, S. (2009). Multilingual strategies of negotiating English: From conversation to writing. JAC, 29(1/2), 17-48. https://www.jstor.org/stable/20866885

Christenbury, L. (Ed.) (1996). The English Journal, 85(7). https://www.jstor.org/stable/i233799

Davila, B. (2006). Rewriting race in the writing center. The Writing Lab Newsletter, 31(1), 1-5.

Hall, J. (2018). The translingual challenge: Boundary work in rhetoric \& composition, second language writing, and WACMID. Across the Disciplines, 15(3), 28-47. wac.colostate.edu/docs/atd/trans/hall2018.pdf

Horner, B. (2017). Teaching translingual agency in iteration: Rewriting difference. In B. Horner \& L. Tetreault (Eds.), Crossing divides: Exploring translingual writing pedagogies and programs (pp. 87-97). Utah State University Press.

Horner, B., Lu, M.-Z., Royster, J. J., \& Trimbur, J. (2011). Language difference in writing: Toward a translingual approach. College English, 73(3), 303-321. https://www.jstor.org/stable/25790477

Horner, B., \& Tetreault, L. (Eds). (2017). Crossing divides: Exploring translingual writing pedagogies and programs. Utah State University Press.

Lu, M.-Z., \& Horner, B. (2016). Introduction: Translingual work. College English, 78(3), 207218. https://www.jstor.org/stable/44075110

Matsuda, P. K. (2014). The lure of translingual writing. PMLA, 129(3), 478-483. https://doi.org/10.1632/pmla.2014.129.3.478

McIntosh, K., Connor, U., \& Gokpinar-Shelton, E. (2017). What intercultural rhetoric can bring to EAP/ESP writing studies in an English as a lingua franca world. Journal of English for Academic Purposes, 29, 12-20. https://doi.org/10.1016/j.jeap.2017.09.001

Medina, C. (2019). Decolonial potential in a multilingual FYC. Composition Studies, 47(1), 273294.

National Council of Teachers of English (1974). NCTE resolution \#74.2. NCTE.

Newman, B. M. (2017). Tutoring translingual writers: The logistics of error and ingenuity. Praxis: A Writing Center Journal, 14(3), 5-9. http://hdl.handle.net/2152/61740

Williams, J., \& Condon, F. (2016). Translingualism in composition studies and second language writing: An uneasy alliance. TESL Canada, 33(2), 1-18. https://doi.org/10.18806/tesl.v33i2.1234

Young, V. (2011). Code meshing as world English. NCTE. 